\title{
Extra-Gastrointestinal retroperitoneal giant stromal tumor complicated with intra-tumoral hemorrhage: case report and literature review
}

${ }^{1}$ Surgical Clinic, University County Hospital Mureş, Târgu Mureş, România

2.Morphopathology Department, University County Hospital Mureş, Târgu Mureş, România

${ }^{3}$ Radiology Department, University County Hospital Mureş, Târgu Mureş, România

${ }^{4}$ Department of Anatomy, University of Medicine and Pharmacy Târgu Mureş, Târgu Mureş România

\begin{abstract}
Gastrointestinal stromal tumors are an uncommon sarcomas with mesenchymal origin that arises in the gastrointestinal tract. Recently, most of the published reports describe such tumors located outside of the gastrointestinal tract, with similar pathological characteristics and are named extra-gastrointestinal stromal tumors. We report the case of a patient suffering for a giant retroperitoneal extra-gastrointestinal stromal tumor, complicated with intra-tumoral hemorrhage. The particularity of this case is the presence of the intra-tumoral hemorrhage in a retroperitoneal extragastrointestinal stromal tumor that grew rapidly in volume (in 1 week).
\end{abstract}

Keywords: extra-gastrointestinal, stromal, tumor, intratumoral hemorrhage

\section{Klara Brinzaniuc}

Department of Anatomy, University of Medicine and Pharmacy Târgu Mureș

Gheorghe Marinescu Str., No. 50, Târgu Mureş, România,

klara_branzaniuc@yahoo.com

\section{Background}

Gastrointestinal stromal tumors (GIST) are an uncommon sarcomas with mesenchymal origin that arises in the gastrointestinal tract [1]. GIST are responsible for only $1 \%$ of gastrointestinal tract tumors. The cellular origin of GIST recently has been proposed to be interstitial mesenchymal stem cell [2]. Each year almost 20 million new cases are diagnosed, among which $20-30 \%$ are malignant $[3,4,5]$. Recently, most of the published reports describe GIST located outside of the gastrointestinal tract, with similar pathological characteristics and are named extra-gastrointestinal stromal tumors. Extra gastrointestinal stromal tumors are often located in the omentum, mesenterum, pancreas, retroperitoneum, diaphragm or abdominal wall. Less than $5 \%$ of cases are located outside the gastrointestinal tract [6,7]. A giant retroperitoneal extra-gastrointestinal stromal tumor, complicated with intra-tumoral hemorrhage has not been reported so far. 


\section{Case report}

A 63-year-old female was admitted to the 1st Surgical Department of the University County Hospital Mures, with fever (38.50 C degree) complaining for abdominal distension associated with discomfort, pain, vomiting and symptoms related to intestinal bowel obstruction. She related that his symptoms arise a week ago and the most complaining symptom was the progressively distension of the abdomen. On physical examination a painful palpable mass in the lower left of the abdomen and an asymmetrical distension of the abdomen was found. CT scan of the abdomen and pelvis demonstrated a large $(18.5 \times 19.3 \times 17.5 \mathrm{~cm})$, heterogenous density (low density alter with high density area), well circumscribed mass, behind the retroperitoneum with mass effect on the stomach, pancreas, and spleen. Exploration reveals also small lymph nodes located in aorto-caval and retroperitoneal space, without any other visceral change.

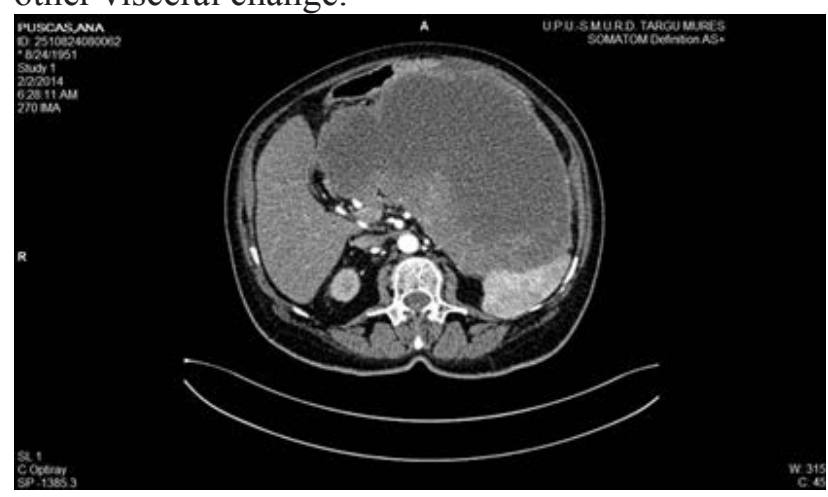

Figure 1 - CT scan of the abdomen shows a heterogeneous mass $18.5 \times 19.3 \times 17.5 \mathrm{~cm}$ behind the peritoneum contiguous anteriorly with the with the stomach, and posterior with the pancreas and spleen

At the clinical examination, the blood pressure was $100 / 70 \mathrm{~mm} \mathrm{Hg}$, and heart rate $105 \mathrm{~b} /$ minute and the other vital signs were normal. Laboratory tests reveal: Hemoglobin $9 \mathrm{~g} / \mathrm{dl}$, and Hematocrit $27.9 \%$, White blood cells $12500 / \mathrm{mm} 3$ and the other blood tests were normal. On the basis of these results we felt confident proceeding with surgical treatment, we performed an extended bilateral subcostal incision, and we examined the abdominal cavity were we found a giant tumor $(20 \mathrm{~cm}$ by $22 \mathrm{~cm}$ ) arise from the retroperitoneum, well-circumscribed mass, purple, with elastic consistency, relatively easy to mobilized compare to below plans. The tumor abutted stomach, pancreas, right kidney and spleen.

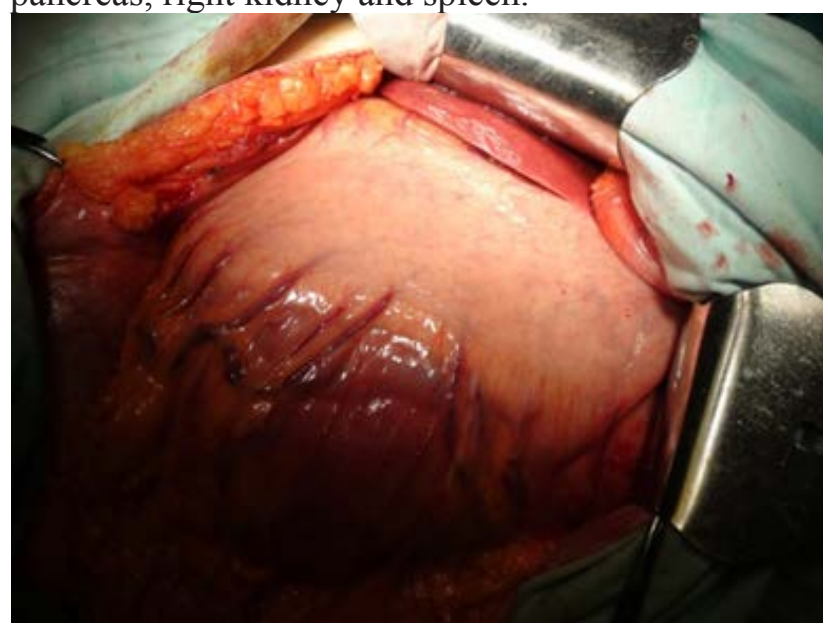

Figure 2 - Gross finding of the giant extragastrointestinal stromal tumor

Intra-operatory the tumor showed heterogenous consistency (liquidian and solid), with intra-tumoral hemorrhage and local necrosis area were found. We elect to perform a large resection of the tumor together with spleen, tail and body of the pancreas, greater curvature of the stomach was removed and the remain margins of the stomach was sutured.

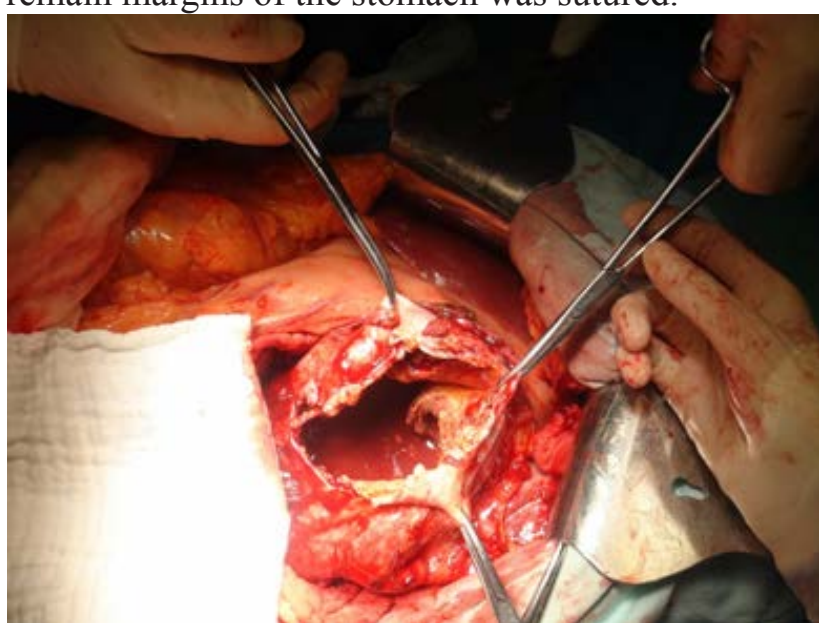

Figure 3 - Intra-tumoral hemorrhage of the extragastrointestinal stromal tumor 


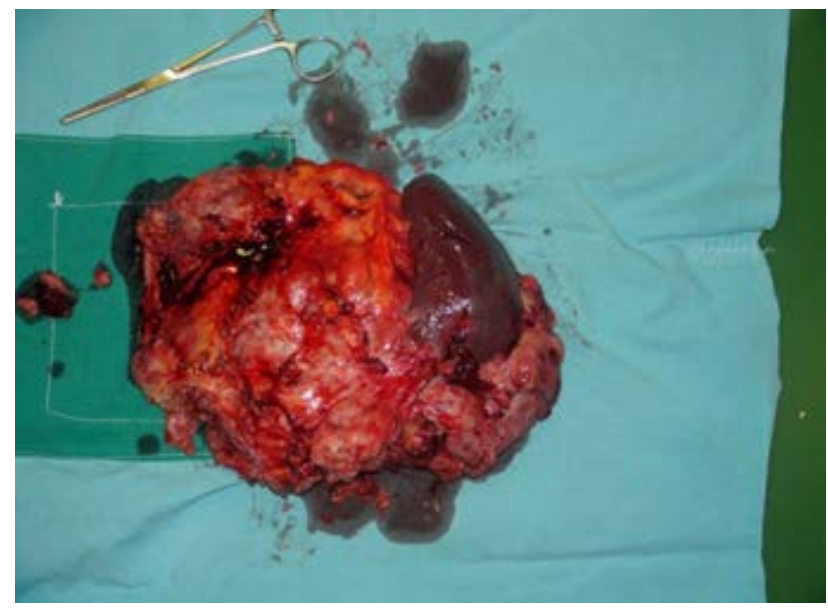

Figure 4 - The resected mass, giant extra-gastrointestinal stromal tumor

The patient did well after the surgical resection; she was discharged from the hospital 2 weeks after her initial presentation.

Pathological examination leads to the diagnostic of stromal tumor located outside the gastrointestinal tract with two degree histological differentiation and high grade of malignancy and with partial wall infiltration. Also, it reveals of the intra-tumoral hemorrhage (Figure 5).

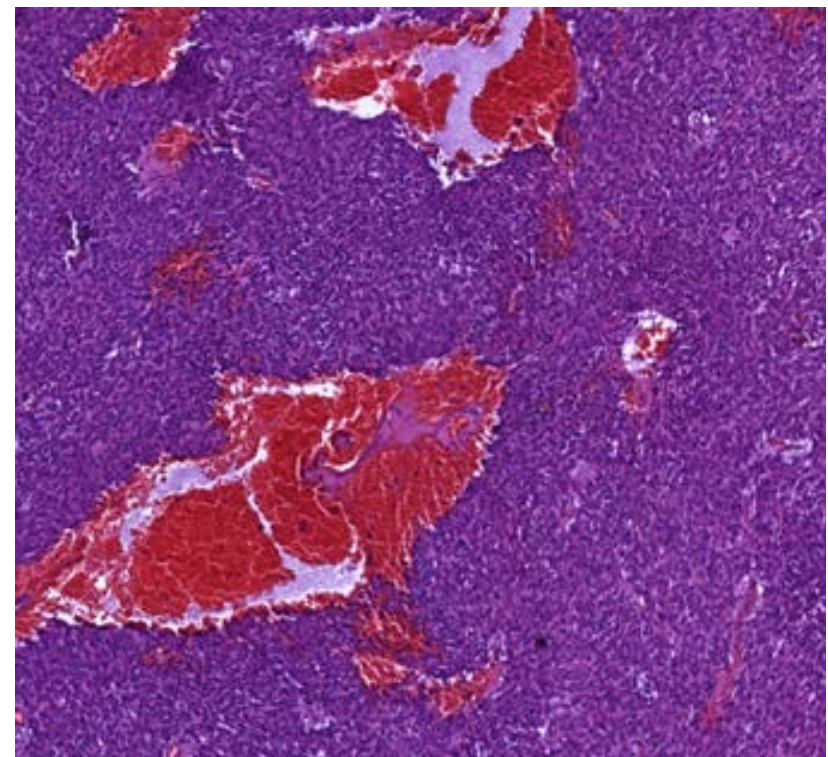

Figure 5 - Intra-tumoral hemorhage Hematoxylin-Eosin, Ob. $20 x$
The malignant tumor contain both stromal and necrosis tissues. Mitotic rate was 30/59 HPF. Imunohistochemical profile showed tumoral cells positive to CD 117, CD 34 and Vimentin and negative to Desmin, SMA and PS 100 (Figures 6,7)

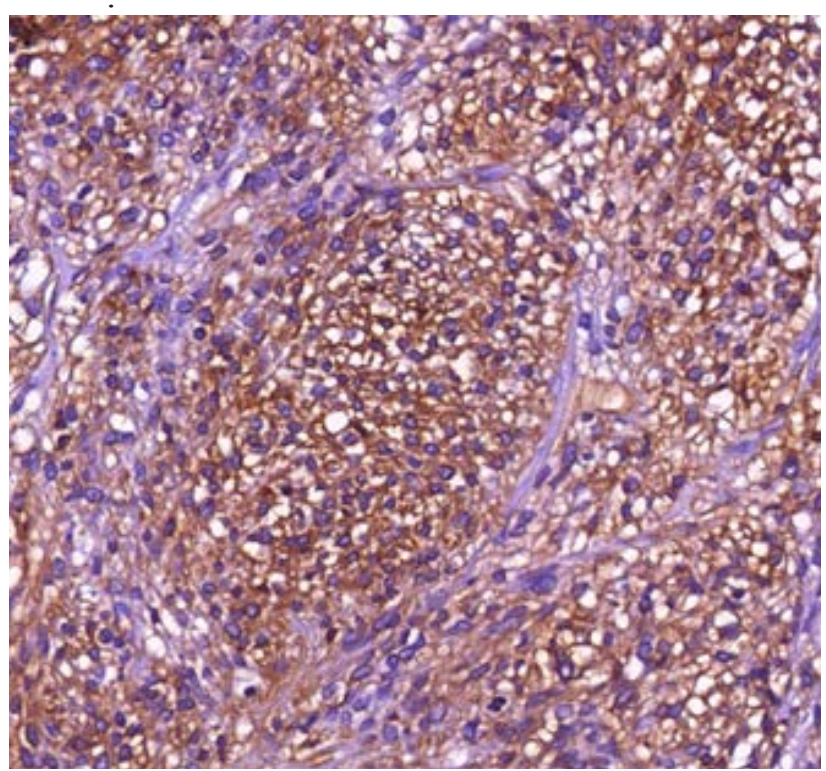

Figure 6 - Tumoral cells CD34 positive, ob. 20x

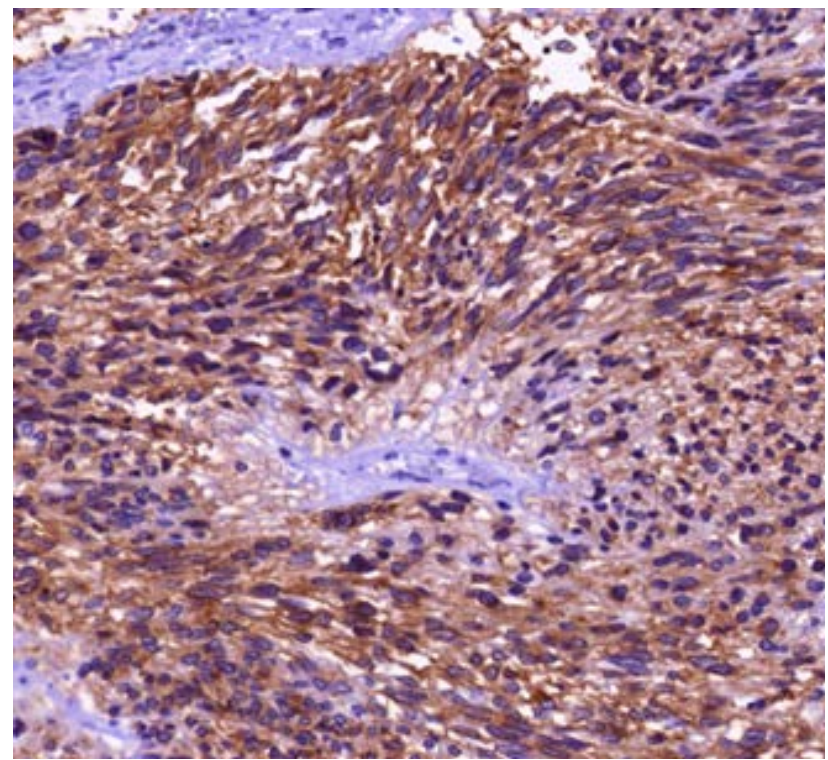

Figure 7 - Tumoral cell CD117 positive, Ob.20x 


\section{Discussions}

Gastrointestinal stromal tumor that arise outside the gastro-intestinal tract, are named extragastrointestinal stromal tumor. $80 \%$ of the extragastrointestinal stromal tumor are located in omentum and mesenterum. Extra gastrointestinal stromal tumors are less often located in retroperitoneum $[6,7,8,9,10,11]$. The literature describes small numbers of cases and the real incidence of this cases is unknown. The clinicopathological features of that tumors, that were histologically similar to gastrointestinal stromal tumors, but have an aggressive course more akin to small intestinal than gastric stromal tumors[13]. Morphologically are described three types of tumors: epithelioid cell, spindle cell and mixed epithelioid and spindle cell [14]. The tumoral cell express CD 117 (c-kit receptor) (95\% of cases), CD34 (70\% of cases), PS 100 (5\% of cases), SMA ( $40 \%$ of cases) and Desmin ( $2 \%$ of cases) $[15,16]$. In very rare cases these tumors can be CD117 negative, and should be examined by using imunohistochemical staining and gene mutation analysis KIT and PDGFR $\alpha$ [17]. Histopathological study is very important and is mandatory to evaluate the mitosis activity $(>2 / 50$ HPF), cellularity and necrosis. In our case the mitotic activity was high and necrosis was present witch significantly increase the risk of worse outcome. The tumor hemorrhage is a seldom complication of the gastrointestinal and extra-gastrointestinal stromal tumors [18]. The literature shows another one case of hemorrhage correlated with large size of a tumor located in the pancreas [19].

Computed tomography examination with contrast was useful and showed the heterogeneous structure of the tumor caused by hemorrhage. The first step in the management of advanced extragastrointestinal stromal tumors is to confirm the diagnosis. This middle age woman had a very large abdominal tumor, he was asymptomatic until recently, and his organ function and results of the laboratory tests were normal. This patient was offered surgical resection and she accepted. The treatment of such cases is surgical and oncologic. The purpose is the large resection of the tumor, the removal of the tumor along with the shell without limfadenectomy because the spread of the tumoral cells does not occur through lymphatic vessels [20].

No conventional cytotoxic chemotherapy, either alone or in combination with radiotherapy is useful in the management of extra-gastrointestinal tumors. New therapeutic approach became available for such cases: imatinib mesylate, formerly known by the code name of signal transduction inhibitor 571 or STI571. The newest study results indicate that Imatinib binds to the ATP binding site of the intracellular portion of the KIT kinase, preventing ATP from binding and eliminating autophosphorilation and, thus, the induction of downstream signaling pathways. The median time necessary for patients to respond to achieve an objective response is approximately three months but it can range to more than one year after the initiation of imatinib therapy [21].

If surgical removal of the extra gastrointestinal stromal tumors is not possible, inhibition of KIT activity with imatinib led to arrest of the proliferation of tumor and imatinib treatment could be maintained as long as it continues to be well tolerated [22].

The particularity of this case is the presence of the intra-tumoral hemorrhage in a retroperitoneal extra-gastrointestinal stromal tumor that grew rapidly in volume (in 1 week).

\section{Conclusion}

Sometimes the clinical outcome of the patients with extra-gastrointestinal stromal tumors is very fast. One of the possible cause of this rapid clinical outcome is the appearance of the intra-tumoral hemorrhage. A giant retroperitoneal extra-gastrointestinal stromal tumor, complicated with intra-tumoral hemorrhage has not been reported so far. 


\section{References}

1. Stamatakos, M., Douzinas, E., Stefanaki, C., Safioleas, P., Polyzou, E., Levidou, G. \& Safioleas, M., (2009). Gastrointestinal stromal tumor - Review. World Journal of Surgical Oncology. 7, 61. DOI:10.1186/1477-7819-7-61

2. Joensuu, H. (2006). Gastrointestinal stromal tumor (GIST). Annals of Oncology. 17(10), 280286

3. Kim, K.M., Kang, D.W., Moon, W.S., Park, J.B., Park, C.K., Sohn, J.H., Jeong, J.S., Cho, M.Y., Jin, S.Y., Choi, J.S. \& Kang, D.Y. (2005). Gastrointestinal Stromal Tumor Committee; The Korean Gastrointestinal Pathology Study Group. Gastrointestinal Stromal Tumors in Koreans: Incidence and the Clinical, Pathologic and Immunohistochemical Findings. $J$ Korean Med Sci. 20, 977-984

4. Tryggvason, G., Gislason, H.G., Magnusson, M.K. \& Jónasson, J.G. (2005). Gastrointestinal stromal tumors in Iceland, 1990-2003: The Icelandic GIST study, a population-based incidence and pathologic risk stratification study. Int $J$ Cancer. 117, 289-293

5. Goettsch, W.G., Bos, S.D., Breekveldt-Postma, N., Casparie, M., Herings, R.M. \& Hogendoorn, P.C. (2005). Incidence of gastrointestinal stromal tumors is underestimated: Results of a nationwide study. Eur J Cancer. 41, 2868-2872

6. Liou, Li-Ren, Mong, Fan-Yun \& Tsao, Min-Jen. (2013). Retroperitoneal Extra-Gastrointestinal Stromal Tumor: A Case Report and Review of the Literature, J Med Sci. 33(4), 211-216

7. Casella, C., Villanacci, V., Daiadda, F., Codazzi, M. \& Salerni, B. (2012). Primary Extra-Gastrointestinal Stromal Tumor of Retroperitoneum, Clinical Medicine Insights: Oncology. Issue 6, 189-197

8. Gun, B.D., Gun, M.O. \& Karamanoglu, Z. (2006). Primary stromal tumor of the omentum: Report of a case. Surg Today. 36, 994-996

9. Miettinen, M., Monihan, J.M., Sarlomo-Rikala, M., Kovatich, A.J., Carr, N.J., Emory, T.S. \&
Sobin, L.H. (1999). Gastrointestinal stromal tumors/smooth muscle tumors (GISTs) primary in the omentum and mesentery: clinicopathologic and immunohistochemical study of 26 cases. $\mathrm{Am}$ J Surg Pathol. 23, 1109-1118

10. Yamamoto, H., Oda, Y., Kawaguchi, K., Nakamura, N., Takahira, T., Tamiya, S., Saito, T., Oshiro, Y., Ohta, M., Yao, T. \& Tsuneyoshi, M. (2004). C-kit and PDGFRA mutations in extragastrointestinal stromal tumor (gastrointestinal stromal tumor of the soft tissue). Am J Surg Pathol. 28, 479-488

11. Alkhatib, L., Albtoush, O., Bataineh, N., Gharaibeh, K., Matalka, I. \& Tokuda, Y. (2011). Extragastrointestinal stromal tumor (EGIST) in the abdominal wall: Case report and literature review. Int J Surg Case Rep. 2, 253-255. DOI: 10.1016/j.ijscr

12. Sung-Soo, P., Byung-Wook, M., Wan-Bae, K., Jae-Woong, C., Ju-Han, L., Yang-Seok, C., Jun-Won, U., Young-Jae, M. \& Hong-Young, M., (2005). Letter to the editor: Malignant extragastrointestinal stromal tumor of retroperitoneum, Acta Oncologica. 44, 497-499

13. Reith, J.D., Goldblum, J.R., Lyles, R.H. \& Weiss, S.W. (2000). Extragastrointestinal (soft tissue) stromal tumors: an analysis of 48 cases with emphasis on histologic predictors of outcome. Mod. Pathol. 13, 577-585

14. Yamamoto, H., Oda, Y. \& Kawaguchi, K. et al. (2004). C-kit and PDGFRA mutations in extragastrointestinal stromal tumor (gastrointestinal stromal tissue), A. J. Surg. Pathol. 28, 479-88

15. Blay, J.Y., Bonvalot, S., Casali, P., Choi, H., Debiec-Richter, M., Dei Tos, A.P., Emile, J.F., Gronchi, A., Hogendoorn, P.C.W., Joensuu, H., Le Cesne, A., Mac Clure, J., Maurel, J., Nupponen, N., Ray-Coquard, I., Reichardt, P., Sciot, R., Stroobants, S., van Glabbeke, M., van Oosterom, A. \& Demetri, G.D. (2005). Consensus meeting for the management of gastrointestinal stromal tumors, Report of the GIST Consensus Conference of 20-21 March 2004, under the auspices of ESMO. Annals of Oncology. 16, 566-578

16. Fletcher, C.D.M., Berman, J.J. \& Corless, C.L. et 
al. (2002). Diagnosis of gastrointestinal stromal tumors: a consensus approach. Hum Pathol. 33, 459-465

17. Nagase, S., Mikami, Y., Moriya, T., Niikura, H., Yoshinaga, K. \& Takano, T. (2007). Vaginal tumors with histologic and immunocytochemical feature of gastrointestinal stromal tumor: two cases and review of the literature. Int J Gynecol Cancer. 17, 928-33

18. Cruz, R.J. Jr., Vincenzi, R., Ketzer, B.M., Cecilio, A.L. \& Cepeda, L.A. (2008). Spontaneous intratumoral bleeding and rupture of giant gastric stromal tumor $(>30 \mathrm{~cm})$ in a young patient. World J Surg Oncol. 15(6), 76

19. Harindhanavudhi, T., Tanawuttiwat, T., Pyle, J. \& Silva, R. (2009). Extra-gastrointestinal Stromal Tumor presenting as hemorrhagic pancreatic cyst diagnosed by EUS-FNA, J. Pancreas (Online), 10(2), 189-191
20. Tiwari, A.K, Choudhary, A.K, Khowal, H., Chaudhary, P. \& Arora, M.P. (2013). Primary Extra-Gastrointestinal Stromal Tumor (GIST) arising from mesentery of small bowel and presenting as abdominal mass: A rare entity. Open Journal of Gastroenterology. 3, 267-271

21. Joensuu, H. (2012). Adjuvant treatment of GIST: patient selection and treatment strategies. Nature Reviews Clinical Oncology 9, 351-58

22. Wang, D., Zhang, Q., Blanke, C.D., Demetri, G.D., Heinrich, M.C., Watson, J.C., Hoffman, J.P., Okuno, S., Kane, J.M., Mehren, M. \& Eisenberg, B.L. (2012). Phase II trial of neoadjuvant/ adjuvant imatinib mesylate for advanced primary and metastatic/recurrent operable gastrointestinal stromal tumors: long term follow-up results of radiation therapy oncology group 0132. Ann. Surg. Oncol. 19, 1074-1080 